\title{
SPECIFICS IN THE APPLICATION OF TEACHING RESOURCES AND SPECIFIC TEACHING AIDS FOR STUDENTS WITH MOTOR IMPAIRMENTS
}

\begin{abstract}
Although we think of the school as a static institution, education is still evolving and changing, including the education of children with disabilities.

With the adoption of the Law of Education in 2019, the Republic of Macedonia begins the process of full inclusion, which means that primary education is institutional, personnel, and content organized in a way that supports the inclusion of all students in regular primary education.

At the proposal of the Bureau for development of the education, the Minister of education and science established NORMS and STANDARDS for space premises, equipment, and teaching aids for primary schools in the Republic of North Macedonia. Although it is stated that specialized teaching aids and resources, as well as assistive technologies, will be used for students with disabilities depending on their individual capabilities and needs, the coverage in the program document is very general.

Hence the need to write this paper, to further determinate the specifications of the usage of teaching resources and aids in the inclusive classroom, specify on which way the teaching resources and aids aimed for typical students will become specialized, and which specific teaching resources, learning aids, and assistive technology are necessary for the student with motor impairments.
\end{abstract}

Key words: primary education, students with motor impairments, teaching resources, teaching aids

"The education in the $21^{\text {st }}$ century will undergo a transformation that starts from the individual and his needs. The new spirit of education should be seen in this fact"

Mile Nenadic

\section{Introduction}

Go back into your thoughts 75 or 100 years. Now go fast ahead to this day. In that period a lot of changes happened in mankind development. We 
think of agriculture 100 years ago and nowadays. We think of the medical practice 100 years ago and today. Can you imagine how transport looks like 100 years ago, and how it is today!? Think about the changes of the 20 century in the area of engineering, fashion, and communication. The transformation is so astonishing, isn't it? While most of us feel nostalgic for the "old good times" hardly anyone will decide to be treated by former doctors, use old communication systems or prefer the old fashion (wearing country traditional clothes or old-fashioned clothes).

The technology and science development, modernization of society, among other things has a huge impact on the attitudes and treatments of people with disabilities. In the last 70 years the changes in the terminology, views, attitudes, caused radical changes in the education of children with disabilities, including children with motor impairments and physical disabilities, highlighting new theories and practices on how best to educate these children (Fox, 2003).

When it comes to inclusion as an inevitable part of the modern educational environment, there is a significant set of considerations in terms of its essentialness - first as a concept, and then as an integral practice of the educational process and the overall social system. Therefore, "providing quality education in an inclusive environment is the greatest challenge in modern education, where the key idea of inclusion and social justice is equality - as a moral principle derived from the meaning of the word - justice" (Bouillet, Kudek-Miroshevich, 2015).

The idea of inclusion dates back to 1994, when it was promoted in the Salamanca Declaration and Action Framework, and refers to a form of education that should provide support for children with special educational needs (SENs) involved in regular schools to enable effective education (Dizdarevikj et all., 2017).

Even before the end of the last century, the prevailing opinion was that special education was more a problem than a solution in providing adequate education for students with disabilities (Uditsky, 2003), which conditioned the acceptance of the system of full inclusion. One of the most convincing arguments in her favor is the attitude that "many students in special education are unfoundedly classified and are probably subject to inferior services, and in some cases to offensive labeling and stereotypes" (Uditsky, 2003, Jordanovska, Cenevska, 2008). It is more than obvious that the concept of special education presents an "obstacle for the development of the inclusion because it releases the other part of the educational system from taking responsibilities of teaching all children" (Rouse M., 2008). The teachers have professional responsibility and obligation to keep pace with the changes in education (Rose \& Howley, 2007). For these reasons, full inclusion, as the most justified practice, means "transformation of schools to take care of all children", in terms of spatial, functional, and program adaptations - which occupy a central place in the inclusive process (Mitchel, 2015). 
With the adoption of the Law on education in 2019 in the Republic of N. Macedonia, begins the process of full inclusion. But today's teachers still face the basic challenge in the classroom - how to achieve effective learning for all students. It is important to remember that even the most experienced teacher would not be able to offer a "ready" response to all challenges that he will face during the teaching. Good teachers constantly review their work and evaluate the reactions of the students to their approach. Based on such a revision, it is possible to identify the specific needs of the students and make adjustments that will ensure their participation in teaching.

The successful realization of the nine years of obligatory primary education depends on the quality of prepared teaching programs, well-educated teaching staff, and appropriate space conditions, including equipment and teaching aids, and resources.

\section{Teaching resources}

Jan Amos Komensky in his book "The Great Didactics", published in 1630 , wrote that in order to learn, students must "see, hear, touch or taste". Sensory experiences form the basis of most intellectual activity.

William Glasser stated that "we learn..."

$\Rightarrow 10 \%$ of what we read;

$\Rightarrow 20 \%$ of what we hear;

$\Rightarrow 30 \%$ of what we see;

$\Rightarrow 50 \%$ of what we see and hear;

$\Rightarrow 70 \%$ of what we are discussing;

$\Rightarrow 80 \%$ of what we are doing (from our experience);

$\Rightarrow 95 \%$ of what we learn from others (in Houff, 2010).

What are learning resources? These are tools that enable facilitate or support the learning process in students, ranging from speech characteristics, vocal quality, facial expression, and gestures, to materials and equipment. Also, they include "teaching aids" such as pens, paper, blackboard, marker, chalk, projector, computer, TV, electronic board, etc. The learning resources are useful for both, students and teachers.

When it comes to students, the resources can increase the learning possibilities, improve the understanding of the subject, and arouse interest, increase motivation, and contribute to positive attitudes toward certain subjects and learning in general.

As for teachers, learning resources can improve, expand or enrich teaching and help establish and maintain a learning environment (Koren, 2013).

In order to be effective, the learning resources must not only be in line with the goals, but they also have to be appropriate for the students regarding their age, previous experiences, and knowledge, as well as the developmental level (limited) and physical possibilities. The students who have never used 
certain resources will need sufficient time to get used to such a resource and use it appropriately. Finally, in limited physical possibilities, such as low vision, hearing impairments, dyslexia, color blindness, and other disabilities, certain resources may be totally inadequate and ineffective.

Based on Article 23 paragraph 1, line 3, and paragraph 3 of the Law on Primary Education ("Official Gazette of the Republic of North Macedonia" No. 161 of 5.8.2019) the Minister of Education and Science established NORMS AND STANDARDS for space-premises, equipment, and teaching aids for a primary school in the Republic of North Macedonia, upon the proposal of the Bureau for Development of Education, with Decision no. 18-6466/2 from 10.7.2020. The document was prepared in order to satisfy contemporary standards and norms for the premises and equipment in the nine-year primary school and among other areas, the area of teaching resources and aids is included. However, the coverage of the teaching resources and aids in the program document is too general, which imposes the need to prepare a special document covering the teaching resources, aids, and materials at the level of primary schools in the Republic of North Macedonia.

The Norms and standards for premises, equipment and teaching resources, and aids for a nine-year elementary school in the Republic of N. Macedonia also refer to inclusive education, according to Article 11 from the Law on Primary Education, and they are reasonably adjusted to the individual needs of the student. But is this really the case will see in the following section where we will single out those parts that refer to the teaching resources and aids for students with disabilities in the first, second, and third developmental period.

- To work with students with disabilities will be used toys, objects, and materials provided for students with typical development from the FIRST developmental period, as well as specific teaching aids and assistive technology, depending on the individual possibilities, abilities, and needs of the student with disabilities.

- To teach the students with disabilities will be used specialized teaching resources and learning aids provided for students with typical development in the SECOND developmental period, as well as specific teaching resources, separate learning aids, and assistive technology depending on the individual possibilities, abilities, and needs of the student with disabilities.

- To teach the students with disabilities will be used specialized teaching resources and learning aids provided for students with typical development in the THIRD developmental period, as well as specific teaching resources, separate learning aids, and assistive technology depending on the individual possibilities, abilities, and needs of the student with disabilities (NORMS AND STANDARDS for premises, equipment and teaching resources for a primary school in the Republic of North Macedonia, 2020). 
The generality of the document was the basis from which arose the need to write this paper, to further highlight the specifics in the use of teaching resources and aids in an inclusive classroom, ie how the teaching resources and teaching aids provided for students with typical development will become specialized, and what specific teaching resources, special teaching aids, and assistive technology are needed for the student with motor impairments.

\section{Classification of the teaching resources}

Before approaching the classification of teaching resources, we appreciate that it is important to define this term. Appropriate terminological understanding is a prerequisite for the appropriate relationship of teaching resources and their application in teaching. Teaching resources appear as intermediaries in the teaching process in transmitting information for the purpose of acquiring knowledge. In that mediation, the teaching aids are located between those who are in a communicative relationship, the one who gives, and the one who receives information: teacher-student or student-student. Because the teaching resources are in the role of mediator between those who interact, they are also called didactic media (medium - the one in the middle - mediator in the communication). But not all technical means are didactic media. The school board, the microscope, the television, the computer, are not media by themselves; they become it when they begin to perform a didactic function, which means when in a planned and systematically organized process they serve to achieve the goals of teaching and learning.

There are numerous attempts for the classification of the teaching resources. The simplest division of the materials on which students acquire knowledge is the division into two groups: one group consists of everything that is in our environment and is not made for the needs of teaching (natural); the other group consists of the teaching media that are made specifically for the successful realization of the teaching process (artificial).

When it comes to the classification of the teaching resources, the most common is the division according to the criterion of the senses that participate in the use of the media. In that sense, the media are divided into visual, auditory, and audiovisual. A special group is text media, computers and language labs, simulators, and trainers.

No matter what learning resources the teacher chooses or creates, it is his responsibility to "revive" them together with his students. We need to remember that learning resources - even the most interactive ones - are just tools, it is the teacher who must use them well and wisely. There is no universal teaching tool whose application can successfully replace other teaching resources - each has its own didactic value. Of course, one didactic tool does not exclude the use of another, but still, it must be taken into account that the tools used during a lesson should complement each other and contribute to the students to gain as complete knowledge as possible at the class. The teacher should use 
those didactic tools which will enable him to explain the content of the teaching unit to the students in the most obvious, best, and easiest way.

\section{Specifics in the application of the teaching resources in the teaching for students with motor impairments}

It is not uncommon for the nature and characteristics of motor impairments and physical disabilities to prevent children from gaining normal experiences, learning about the environment, moving, and exploring. The condition becomes even more difficult due to the frequent separation from the natural environment and the parents due to hospital treatments or rehabilitation, which is the reason for insufficient stimulation, during which the child becomes inert, unmotivated, disinterested. All this leads to a lag in a number of cognitive functions, but most often it is the disorder or poor development of perceptual functions, especially the ability to determine certain qualities of objects, to determine a cause-and-effect relationship. Hence the need to apply specially selected, specific, adjusted teaching aids and resources.

\section{Auditory teaching resources (Audio media)}

All those messages that are received with the sense of hearing are sent through auditory teaching resources. Auditory teaching resources are widely used in working with students with motor impairments. They are close to the sounds that most of these students, due to immobility, hospitalization, or home accommodation, are not familiar with. These tools are of great importance for the development of auditory perception, auditory discrimination, auditory attention, and rhythm. However, certain rules must be followed when applying them. In children who have a disorder in auditory perception, and the teaching resource has the task of capturing an event in nature, this tool can be used only by following the rule: one listening - one sound. We should also be careful when making sounds to students who have been diagnosed with epileptic seizures, as sudden and loud noises can provoke them.

\section{Visual teaching resources (Visual media)}

Most of the impressions of the reality we receive through the sense of sight. Hence, visual media are more important than auditory ones in the teaching process. Visual teaching resources, depending on the dimension, can be: two-dimensional and three-dimensional, and given the didactic purpose can be: static and dynamic. Visual media often complement other media, although they can also be used independently. The use of these media is based on the fact that they are less abstract than printed materials and human resources.

In students with motor impairments in which visual impairments are comorbidity, when using visual teaching media, it is necessary to increase the two-dimensional teaching media, with reduced or adjusted number of details, 
with a clear contrast between images and background, with strong colors and be as realistic as possible. Also, care should be taken, if more teaching resources are used in the class, they should be arranged in such a way that first only one will be used, then the same will be removed, and the second will be displayed, etc. to avoid distracting students. For these students, the rule of quickly changing activities and combining teaching resources from different groups during the class also applies. Short-term and long-term memory problems also require a reduced number of details to allow enough time for repetition of the content, thus helping students memorize the material.

The three-dimensional teaching resources (models, objects from the indirect and direct surroundings) have to follow, above all condition of the visual perception, but also the condition of the motoric of the student with motor impairments. In addition to the participation of visual perception, tactile perception is also of great importance, ie the ability to touch, hold and manipulate them. Therefore, the objects and models used in working with students with motor impairments should be adjusted in size to allow independent work.

When the three-dimensional teaching resources are used care should be taken to ensure that they are safe to use, ie that they do not cause injury to the student or worsen their health condition (this is important for all students, but is extremely important for students suffering from diabetes, hemophilia, bronchial asthma or other allergies).

\section{Textual teaching resources (Printed materials)}

In some classifications of the teaching resources, printed materials are labeled as a subgroup of the visual teaching resources. This group primarily includes books, then manuals, programmed texts, columns, proceedings, etc. The books are primary learning resources, while other materials are considered secondary learning resources. The printed materials should be didactically formatted in order to acquire their teaching function. The text should be logically systematized, divided into thematic sections and units, understandable for the age, logically connected with the previous knowledge of the student, to be illustrated with drawings, to have questions and exercise tasks.

Application of the printed material in students with motor impairments requires numerous adjustments. The way of the adjustment of the materials depends on the age of the students, their lexical abilities, but also on the necessary reading skills, which are visual perception, spatial orientation, memory, and attention. In addition to the above, how the text materials will be adapted also depends on the manipulative abilities of the students.

The length of the text and tasks have to be in correlation with the level of the developed lexical abilities of the students for the given letter and given age. Given that in the special education and rehabilitation of persons with motor impairments we primarily talk about abilities, and less about age, then here too some adjustments need to be made. Completely different lengths of the text in the worksheets will be given to students who have mastered the reading com- 
pared to the students who read letter by letter and have difficulties in connecting the letters in syllables and syllables in words.

For students who have problems in spatial orientation and following the rows, and the condition of the motor functions of the upper limbs is such that the student cannot underline the row with his finger, application of the text teaching resources requires an active role of the teacher. The teacher can cover the rows which the student should not read at the moment, giving him the opportunity to see the line that needs to be read. The adaptation can be done with the help of special sheets on which one sentence is written, ie one line, which the student should read. The reading is done by changing the separate sheets. The teacher can adapt the textual teaching resource by increasing the text, increasing the visibility of the letters (color, thickening), underlining the important parts of the text, etc. (Ilic-Stosljevic, 2011).

The presence of the spasticity, choreatic, and athetoid movements on the upper limbs and/or head and neck significantly complicates the application of textual teaching resources, and primarily the literacy process itself. In order for the student with involuntary movements to use text teaching resources, they should be made of hard cardboard. If the student also has increased salivation (drooling occurs in students with cerebral palsy, muscular dystrophy, and head injury) such a teaching tool must be plasticized to be easier to erase and use longer.

\section{Audiovisual teaching resources (Audiovisual media)}

The title itself says that these are tools that require the use of two senses: sight and hearing. Audiovisual media are also important when material objects or the natural environment are not available. The camera can record places that most people cannot see or visit (for example, sea depths, cultural and historical sites), to help students understand certain processes that are not visible or recognizable because they are too fast, too slow or too small, slowing down fast-moving events or speeding up events over long periods of time (using timelapse photography can show the growth of a plant). Modern audiovisual media are: teaching movies, educational shows and DVDs.

However, using audiovisual media in the inclusive classroom is not always easy. When applying them all rules regarding the use of visual and audio media should be observed. Specifically, the length of the film or other audiovisual presentation should be tailored to the state of memory and attention of students with motor impairments. The content, the interruptions in the broadcast, the frequency of the explanations, which are necessary to understand the content of the audiovisual presentation, are primarily conditioned by the state of the students' visual and auditory abilities, but also by the state of attention and memory, the presence of epileptic seizures, the degree of student fatigue, the level of operativeness of the opinion, etc. 


\section{Specific aids and equipment in the teaching of students with motor impairments}

Specific aids that will enable the smooth running of the educational process are needed for students with motor impairments.

The first and most important thing for active participation in the class and encouraging the application of the hands is the correct positioning of the student. The student's positioning may involve the whole body or only one part, for example, the arm. The advantage of good positioning is that it facilitates movements by the body not having to work against gravity. Facilitating movement also means that the child must use less conscious energy to maintain his position. Good positioning means optimizing symmetry and stability (Fox, 2003).

The symmetry means keeping both sides of the body even - the body should be in the middle line. For many children with physical disabilities, there is a tendency for the body to assume an incorrect position, which can be seen when the body is tilted to the left or right or sliding down through the chair. Such positions not only cause long-term problems but also mean that the child is not in the best position for learning and communication (Rashikj-Canevska, Chichevska-Jovanova, 2021).

Stability means the ability to keep the body in the desired position. The more the body can be stabilized, the less effort the child has to invest in maintaining the position. A key aspect of maintaining stability is head control. In order for the child to be able to actively learn and attend classes, he should be able to keep his head upright. Without this he cannot focus on his work, can not read or follow the instructions of the teacher. The head should be straight, in the middle line, slightly bent forward (Fox, 2003). Proper positioning of the child is possible only by providing the necessary support/equipment (Picture 1).

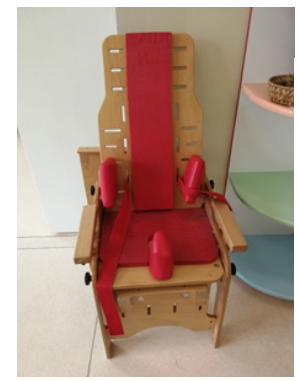

Pic. 1.

Positioning chair

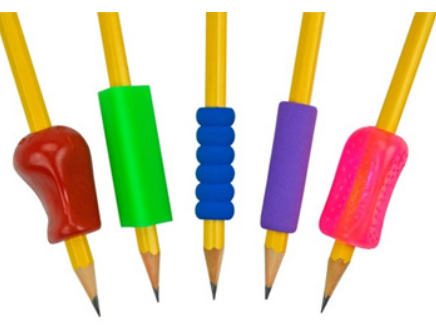

Pic. 2. Pencil covers

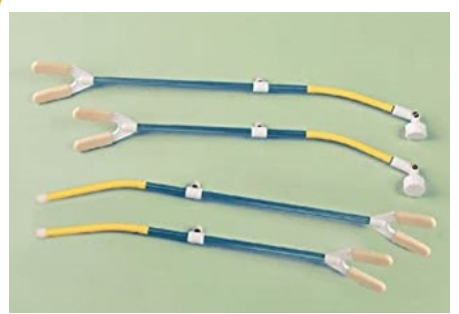

Pic. 3. Mouth writing covers 
The working desk of the students with motor impairments should be larger than ordinary desks, which will allow them to easily organize the workspace, which will prevent inadvertent pushing of objects. The substrate should be specially prepared because many students are not able to write with one hand (dominant) and hold the material with the other, so the substrate should be sticky to prevent slipping.

Success in writing will also depend on the equipment used in writing. There are different shapes of pencils: round, triangular, hexagonal, etc., but the use of a triangular shape extends the effective writing time by $300 \%$. Pencils and other writing utensils can be of different dimensions (thickness), but an optimal thickness is $7.15 \mathrm{~mm}$. In cases when we do not have the optimal volume of the pencil or for students with insufficiently differentiated fine motor skills, different covers for the accessories are applied, which will increase the volume (Pic. 2). Effective writing and fatigue also depend on the holding height of the utensils, and the optimal height is set at 15-37mm. (Stoshljevic et all, 1990).

In cases of severe motor impairment or absence of the upper extremities, one of the methods used is mouth writing, which is the most effective form after handwriting. The pencil or utensil is placed on an extension, which at one end has a cover that is placed in the mouth and is held by biting it with the teeth. The cover should be kept clean, and when it is deformed or damaged, it should be replaced, so as not to damage the teeth and gums. The length of the writing extension should be $16-18 \mathrm{~cm}$ (Pic. 3). If it is shorter it will cause eye fatigue and vision problems, otherwise, when it is longer it will cause difficulties in controlling the writing process and neck fatigue. The extension can also be used to work on a keyboard or to use assistive technology.

$\mathrm{Head} /$ forehead writing is a rare way of writing used by students with quadriplegia and a severe form of general motor impairment. A wristband is placed around the head on the student's forehead on which various extensions for writing or applying assistive technology are mounted.

For students with motor impairments, who move independently or with aids and have problems maintaining balance, it is necessary to place a handle (holder) under the school board so that the student can use the board smoothly with adherence.

There is often a question if there is a need for the school to provide assistive technology for the students who need it most. According to the Act for Education of Persons with Disabilities, it is necessary to use assistive technology for all students for whom individual educational plans (IEPs) are developed. The Technology Assistance Act (1988) defines assistive technology as "any item, piece of equipment or system of products, whether commercially purchased, modified or specially designed or specially constructed" used to increase, maintain or improve the functional abilities of persons with disabilities". Assistive technologies are divided into two main categories: "high tech" referring to complex software programs, voice generating devices, etc. and "low tech", including the simplest aids such as a cane, dressing aids, etc. (Legislative History-USA 
in Congress assembled., 1988). Regarding the purpose, assistive devices can be divided into (NIH, 2018): mobility aids (wheelchairs, canes, pacers, prostheses, etc.); communication aids (voice board, voice generator); aids to facilitate the learning process (text reader - text to speech, oral to written converter, customized and alternative input devices, voice calculator, electric page-turner, etc.); aids to increase functionality (oral telescopic orthosis); cognitive aids (computers, tablets, smartphones or other electrical devices that will improve memory, user orientation).

\section{Conclusion}

The educational system aims to provide the student with conditions for the smooth running of the educational process and vertical passage. There are no specific rules and determinants for the type and manner of use of teaching resources, aids, and assistive technology in correlation with IOP, but when they are properly included and applied, the probability that the student who uses them will be more effective, better will use its potentials and will be successfully included.

\section{References}

Bouillet, D., Kudek-Miroshevich, J. (2015). Students with Disabilities and Challenges in Educational Practice In Prskalo I, editor. Croatian Journal of Education; 17 (2): 11-26.

Fox, M. (2003). Including children 3-11 with physical disabilities. David Fulton Publishers. Rouse M. Developing Inclusive Practice: A role for Teachers and Teacher Education? In Education in the North 2008; 6 (1): 1-20.

Houff, S.G. (2010). The classroom facilitator Special Issue Questions. United Kingdom: Rowman \& Littlefield Education.

LEGISLATIVE HISTORY. (1988). Technology-Related Assistance for Disabilities Act. In PUBLIC LAW 100-407-AUG. 19, 1988.

Mitchel, D. (2015). Inclusive Education is a Multi-Faceted Concept In Devetak I., editor. Centar for Educational Policy Studies Journal; 5 (1): 9-30.

National Institutes of Health. (2018). What are some types of assistive devices and how are they used?. [cited 2020] Available from URL: https://www.nichd. nih.gov/health/topics/rehabtech/conditioninfo/device

Uditsky, B. (2003). From Integration to Inclusion: The Canadian Experience In Slee R., editor. Is There a Desk with My Name on It?: The Politics of Integration. Abingdon: Routlege.

Dizdarevic, A. et all (2017). Sporedba na stavovite na nastavnicite za inkluzivnoto obrazovanie vo Bosna I Hercegovina I vo Evropskata unija (Comparison of the teacher's attitudes toward inclusive education in Bosnia and Herzegovina and European Union). In Journal of special education and rehabilitation; 18 (1-2): 92-108. 
Ilic-Stoshljevic, D. (2011). Teorija vaspitanja I obrazovanja osoba sa motornim poremechajima (Theory of education of persons with motor impairments). Beograd: Fakultet za specijalnu edukaciju I rehabilitaciju - Izdavachki centar (CIDD).

Jordanovska., Zh., Cenevska, Z.O. (2008). Posebni obrazouni potrebi: rabota so uchenici so posebni obrazovni potrebi (Special education needs: working with students with SEN). Skopje: Algoritam Centar.

Koren, S. (2013). Resursi za uchenje (Learning resources). In Nastava za da se nauchi: referenten vodich za nastavnici orientirani kon rezultati (Teaching for learning: referent guide for teachers oriented to results). Beograd: Gama Digital Centar.

NORMATIVI I STANDARDI za prostor, oprema I nastavni sredstva za osnovno uchilishte vo Republika Severna Makedonija (Norms and standards for premises, equipment and teaching resources in primary school in the Republic of North Macedonia) (2020). [Cited 2021] Available at https:// mon.gov.mk/stored/document/Normativi\%20i\%20standardi\%20za\%20 osnovno\%20uciliste.pdf

Rashikj-Canevska, O., Chichevska-Jovanova, N. (2021). Metodika na rabota so uchenici so motorni narushuvanja (Methodic of work with students with motor impairments). Skopje: Filozofski fakultet.

Sluzhben vesnik na RSM (Official gazzete), No. 161 from 5.8.2019 year. Low of Primary Education.

Stoshljevic, L., Rapaic, D., Nikolic, S. (1990). Somatopedia. Beograd: Nauchna Knjiga. 